\title{
CARTELES DE FIESTAS. ANÁLISIS DOCUMENTAL E ICONOGRÁFICO
}

\author{
Carolina Cadenas Pazos*
}

Documentalista.

\author{
Antonia Salvador Benítez,**
}

Universidad Complutense de Madrid.

\begin{abstract}
Resumen: Estudio y análisis documental de los carteles de fiestas como una tipología específica del cartel publicitario. Se realiza el análisis documental e iconográfico de 71 carteles de las fiestas de San Isidro Labrador y se describen sus características empleando una ficha de análisis de diseño propio. A nivel visual, los resultados muestran cómo se han representado y cómo se venden los motivos festivos madrileños a través de este medio publicitario. Desde el punto de vista documental e informativo, el análisis cuantitativo y cualitativo de la muestra ha permitido la identificación de los artistas autores de los carteles, los formatos, técnicas y soportes utilizadas, así como los elementos iconográficos, temas, personajes y lugares más representados en los carteles.
\end{abstract}

Palabras clave: Análisis documental; análisis iconográfico; cartel publicitario; diseño publicitario; identidad visual.

Title: FESTIVITIES POSTERS. ICONOGRAPHIC AND DOCUMENT ANALYSIS.

Abstract: Estudy and document analysis of the festivities posters as a kind of advertising poster. There is a description of the basic features of 71 representative posters of San Isidro Labrador festivities using a self design model for this study. Visually, the results show how are represented the festive elements of Madrid through this advertising medium. From the documentary perspective, quantitative and qualitative analysis of the sample has allowed the identification of the authors of the poster, formats, techniques and the iconographic elements, themes and places most represented on posters.

Keywords: Advertising design; advertising poster; documentary analysis; iconographic analysis; visual identity.

\section{INTRODUCCIÓN.}

El cartel ha demostrado ser un medio de expresión vivo de gran trascendencia publicitaria y estética que en algunos momentos ha conseguido alcanzar la categoría de arte, adquiriendo un lugar destacado a partir de 1880 . Se trata de un medio de comunicación de masas que nació para ser expuesto públicamente, dentro de una población que se movía a pie. De tamaño variable, utiliza un soporte de dos dimensiones, efímero y de naturaleza frágil (papel, cartón, tela o lienzo). Su principal objetivo es comunicar un mensaje de forma clara y sencilla sirviéndose de los lenguajes icónico y textual. Además de esta naturaleza informativa, destaca también su carácter perecedero y en ocasiones, su afán persuasorio.

Según la Real Academia Española RAE, cartel es la lámina de papel u otra materia en que hay inscripciones o figuras y que se exhibe con fines noticieros, de publicidad, etc. Además de soporte publicitario, el cartel es un medio de comunicación que se difunde en los espacios públicos y que posee unas características propias que difieren de otros medios. Se trata del único medio publicitario autónomo, ya que se configura de forma independiente a la prensa o a cualquier otro medio de comunicación de masas, al igual que su modo de recepción, que opera de forma diferenciada a la del resto de los anuncios en general.

El cartel constituye una pieza singular con ingredientes artísticos y de información de gran interés. Propio de exteriores urbanos, su mensaje inmediato y efímero se vuelve trascendente con el paso del tiempo, y al igual que ocurre con los sellos, postales, o monedas, se convierte en objeto de coleccionismo tanto a nivel privado como por parte de las instituciones públicas.

El origen del cartel moderno se sitúa en el siglo XIX, con el comienzo de la utilización de los medios de impresión litográfica a tres tintas (roja, amarilla y azul) que permitía una gran variedad de tonos y texturas. Caracterizado por su lenguaje claro y directo, desde sus inicios el cartel permitió a artistas como Jules Chéret o Alphose Mucha, expresar ideas de una forma directa y sencilla y conectar con el público. El perfeccionamiento de las técnicas de impresión y la explosión del color, modificaron profundamente el concepto del dibujo y la comunicación.

\footnotetext{
* carolinacapazos@gmail.com

**asalvador@ccinf.ucm.es
} 
Los movimientos sociales y políticos del siglo XX también jugaron un papel importante en la historia del cartel. Las dos guerras mundiales, la revolución tecnológica, el comunismo o el fenómeno hippie crearon un lenguaje directo y una estética atractiva para el público.

Otros hitos importantes en esta evolución fueron la revolución industrial, el desarrollo de las economías capitalistas y su ruptura con el bloque socialista. También ejercieron una gran influencia los diferentes movimientos artísticos como el Art Noveau, Simbolismo, Futurismo, Cubismo, Constructivismo, Expresionismo, Surrealismo o Realismo. Pero también el cartel llegó a ejercer influencia en los artistas de estas diferentes tendencias como Henry Toulouse-Lautrec o Cassandre.

En la actualidad, el cartel se ha convertido en un instrumento publicitario tan extendido y cotidiano que ha perdido eficacia como medio de comunicación y cada vez es más compleja su función apelativa, circunstancia que va a obligar a los artistas y creativos a agudizar el ingenio para captar la atención del viandante.

El presente trabajo aborda el estudio del cartel publicitario, concretamente una tipología singular como son los carteles de fiestas de carácter público e institucional convocadas por ayuntamientos y otros organismos públicos que aúnan celebraciones religiosas, verbenas, bailes y corridas de toros. Con Madrid como escenario se analizan los carteles correspondientes a las fiestas de San Isidro Labrador en su vertiente taurina y religiosa. El conjunto de carteles objeto de estudio abarca una cronología que se inicia en 1947, fecha del primer concurso de carteles de las fiestas patronales organizado por el Ayuntamiento de Madrid, hasta el año 2005.

Como antecedente podemos destacar la exposición "Carteles de fiestas en la colección del Museo Municipal (1932-1991)" en cuyo catálogo se recogen los carteles que forman parte de los fondos del museo y que corresponden a distintas festividades de la capital, entre ellas las de San Isidro. En cuanto a la vertiente taurina, no se ha encontrado ningún trabajo que estudie de forma monográfica los carteles de los festejos taurinos de San Isidro. La principal contribución de este trabajo es ofrecer de forma específica un estudio documental e iconográfico de las fiestas de San Isidro Labrador a través del cartel taurino y de fiestas, ofreciendo una visión integrada del conjunto de carteles dispersos en distintos centros e instituciones de la capital.

\subsection{Objeto de la investigación.}

La tradición y el origen campesino de Madrid se ven reflejados en los festejos y actividades lúdicas colectivas en las que suelen ir de la mano el factor religioso y el taurino. Desde San Isidro hasta la Virgen de la Paloma, Madrid aprovecha la ocasión para asistir a procesiones, acudir a corridas de toros y disfrutar de las verbenas a la caída de la tarde. Los carteles se convertirán en el principal instrumento publicitario de estas fiestas y actividades. A través del estudio del cartel de fiestas podemos conocer el panorama plástico de una determinada localidad, las tendencias de cada período así como la evolución de las tradiciones y actividades lúdicas asociadas a la fiesta.

Este trabajo reúne los principales carteles de las fiestas de San Isidro Labrador en su vertiente religiosa y taurina con objeto de realizar un estudio documental e iconográfico de este medio publicitario que nos permita conocer cómo se ha representado y cómo se venden los motivos festivos madrileños a través de este soporte. Para ello se plantean los siguientes objetivos:

- Localización y recopilación de los carteles correspondientes a las Fiestas de San Isidro Labrador en Madrid, referidos tanto a las celebraciones lúdicas y religiosas como a los festejos taurinos en el período que abarca desde 1947 hasta 2005.

- Análisis documental de los carteles localizados diseñando para ello un modelo de ficha descriptiva que permita la caracterización de los aspectos formales y de contenido de cada una de las piezas de la muestra, en sus variantes taurina y religiosa.

- Análisis iconográfico de los carteles para identificar los motivos e iconos que se han empleado para representar e ilustrar la fiesta madrileña a través de este soporte, durante el período estudiado.

- Identificación de los artistas creadores de los carteles y su particular visión de la fiesta.

\section{METODOLOGÍA.}

El estudio de los carteles de fiestas patronales viene justificado por ser una tipología de gran tradición y arraigo en nuestro país que ha sido escasamente estudiada. Por otro lado, la ciudad de Madrid resulta un escenario idóneo por tratarse, en primer lugar, de un entorno conocido y abarcable, y en segundo lugar, por la popularidad de las fiestas en honor de su patrón, San Isidro Labrador. 
La muestra de estudio se compone de un total de 71 carteles -42 correspondientes a las fiestas y 29 a los espectáculos taurinos- desde 1947 hasta 2005. El procedimiento habitual para el diseño y elección del cartel de las fiestas populares ha sido la realización de concursos de carteles, celebrándose el primero en 1947. En el presente trabajo han sido objeto de estudio los carteles ganadores de cada edición, descartando los carteles presentados a concurso (e incluso premiados) que no obtuvieron el primer premio. También se han descartado los bandos y notas de prensa referidos a la fiesta anteriores a 1947.

En una primera fase, la búsqueda y localización de los carteles se realizó a través de los catálogos online de la Biblioteca Nacional de España, REBIUN, la Biblioteca Regional Joaquín Leguina de la Comunidad de Madrid, así como de la web Memoria de Madrid < http://www.memoriademadrid.es>. También han sido de gran utilidad las consultas realizadas en las hemerotecas de los diarios $\mathrm{ABC}<\mathrm{http}$ ://hemeroteca.abc.es $>$ y El País $<$ http://elpais.com>. Esta fase se completó con la visita a varios museos, bibliotecas y archivos para conocer de primera mano la existencia de ejemplares sobre la temática y su estado de conservación. Los centros que se han visitado son la Biblioteca Nacional de España, Biblioteca Histórica del Conde Duque, Museo Taurino de las Ventas, Archivo Regional de la Comunidad de Madrid, Círculo de Bellas Artes, Museo de Historia de Madrid, Museo del Traje y la Biblioteca Regional Joaquín Leguina de la Comunidad de Madrid, encontrando varias versiones de algunas ediciones.

\begin{tabular}{|l|c|c|}
\hline Localización & Cartel taurino & Cartel de fiestas \\
\hline Museo del Traje & -- & 2 \\
\hline Museo de Historia de Madrid & 7 & 42 \\
\hline Biblioteca Nacional & 1 & 6 \\
\hline Biblioteca Regional Joaquín Leguina de Madrid & 25 & -- \\
\hline
\end{tabular}

Tabla I. Localización de ejemplares en las instituciones.

A continuación se procedió a la selección de la muestra de estudio que se compone de un total de 71 carteles (42 de fiestas y 29 taurinos) del período comprendido entre 1947 y 2005 . El criterio empleado para la selección de la muestra ha sido de carácter cronológico, tomando como referencia el año en que se celebran los primeros concursos de carteles de fiesta, y el inicio la Feria taurina de San Isidro. En ambos casos se trata del año 1947, sin embargo, el primer cartel taurino encontrado data de 1952, razón por la que los carteles estudiados pertenecientes a esta tipología se inician en dicha fecha.

Una vez seleccionada la muestra, se procedió al diseño de una ficha para la descripción y consigna de las características formales y de contenido de los carteles de fiestas y taurinos. Para ello han servido de referencia los catálogos impresos y en línea disponibles en los propios centros de custodia, cuyas fichas hacen referencia al número de inventario, autor, datación, dimensiones, técnica y soporte, firmas e inscripciones. Sin embargo, estos modelos resultaban insuficientes para la descripción del contenido iconográfico de los carteles por lo que ha sido necesario diseñar un modelo de análisis documental adaptado a las necesidades específicas del presente estudio.

La ficha descriptiva comprende dos niveles de análisis, formal y de contenido. El análisis formal va a permitir identificar a los artistas autores de los carteles, el estilo, las técnicas empleadas y los formatos. En el análisis de contenido van a tener especial incidencia los elementos iconográficos, identificando los motivos, temas, escenas y símbolos que se han empleado a lo largo de los años para representar la fiesta de San Isidro. La ficha de análisis diseñada cuenta con la siguiente estructura:

\section{Análisis Formal}

- $\quad \mathbf{N}^{\mathbf{0}}$ de Registro: Número interno asignado a la pieza. Se sigue un orden por tipología (primero fiestas y a continuación taurino) y cronológico.

- Centro: Nombre de la institución (archivo, museo, biblioteca, etc.) donde se ha localizado el cartel. Tras el nombre, se indicará el número de inventario asignado en dicho centro. En caso de hallarse en más de un centro, se indicará. Ejemplo: Biblioteca Nacional de España (AHC/3455); Museo Municipal (R/135).

- Lugar: Lugar donde se celebran los festejos o la corrida. Si el lugar no consta en la pieza y se localiza en otras fuentes, se indicará entre corchetes [ ]. Ejemplo: [Madrid].

- Título: Título formal (asignado por la institución de custodia) o título atribuido durante el estudio. Ejemplo: Fiestas de San Isidro de 1949.

- Datación: Fecha de impresión del cartel.

- Autor: Artista que ha realizado el diseño del cartel. Si la información no consta en la pieza y se localiza en otra fuente, se indicará entre corchetes []. Ejemplo: [Teodoro Delgado]. 
- Firma: Se indicará si consta la firma del autor y, en caso afirmativo, la posición en el cartel. Ejemplo: Sí, esquina superior derecha.

- Editor: Empresa editora del cartel. Si la información no consta en el cartel y se localiza en otras fuentes, se indicará entre corchetes [ ]. Ejemplo: [Sección de Cultura-Artes Gráficas Municipales-Madrid].

- Dimensiones: Medidas exteriores del cartel. Se indicará: alto x ancho, en centímetros.

- Soporte: Material en el que está impreso el cartel (papel, cartón, tela o lienzo).

- Técnica: Técnica empleada para el diseño del cartel.

- Tintas: Los ejemplares en blanco y negro se acompañarán de la indicación 'b/n'. En los ejemplares a color se indicará 'Color' y el número de tintas utilizadas. Ejemplo: Color; cuatro tintas.

- D.L.: Número del depósito legal del ejemplar. Si no consta se indicará con guión '-'.

- Análisis de Contenido

- Texto: Trascripción del texto o leyenda del cartel. Se mantendrán las mayúsculas y minúsculas, y se indicará cada cambio de renglón mediante el símbolo '/'. Ejemplo: FIESTAS de/ SAN ISIDRO/ MADRID 1955.

- Imagen: Breve resumen del diseño e imagen del cartel.

- Programa: Conjunto de nombres propios presentes de manera textual en el cartel. Esta área de información es específica de los carteles taurinos, ya que en los carteles de fiestas no consta el programa.

- Descriptores: Conceptos, temas, lugares y nombres de personas o instituciones representadas en el cartel. Se unifican en este apartado los descriptores geográficos, onomásticos y temáticos.

- Notas: Apartado dedicado a información presente en el cartel ajena a cualquier apartado anterior. Sólo constará en los carteles donde se considere necesario.

Para favorecer la posterior búsqueda, recuperación y reutilización de la información descriptiva se ha trasladado este modelo descriptivo a una base de datos empleando el programa FileMaker que permite - además del diseño personalizado de los campos que conforman el registro y las funcionalidades propias de cualquier sistema de gestión documental - insertar las imágenes asociadas a cada registro, facilitando la descripción y la identificación de cada uno de los ejemplares analizados. Además ha facilitado la elaboración de índices y estadísticas atendiendo a criterios cronológicos, temáticos, autoría, formatos, soportes, etc. En total se han localizado y descrito de forma individual 71 carteles.

Los ejemplos 1 y 2 muestran el modelo de análisis documental propuesto aplicado a las dos tipologías de carteles (de fiestas y taurinos) objeto de estudio. 


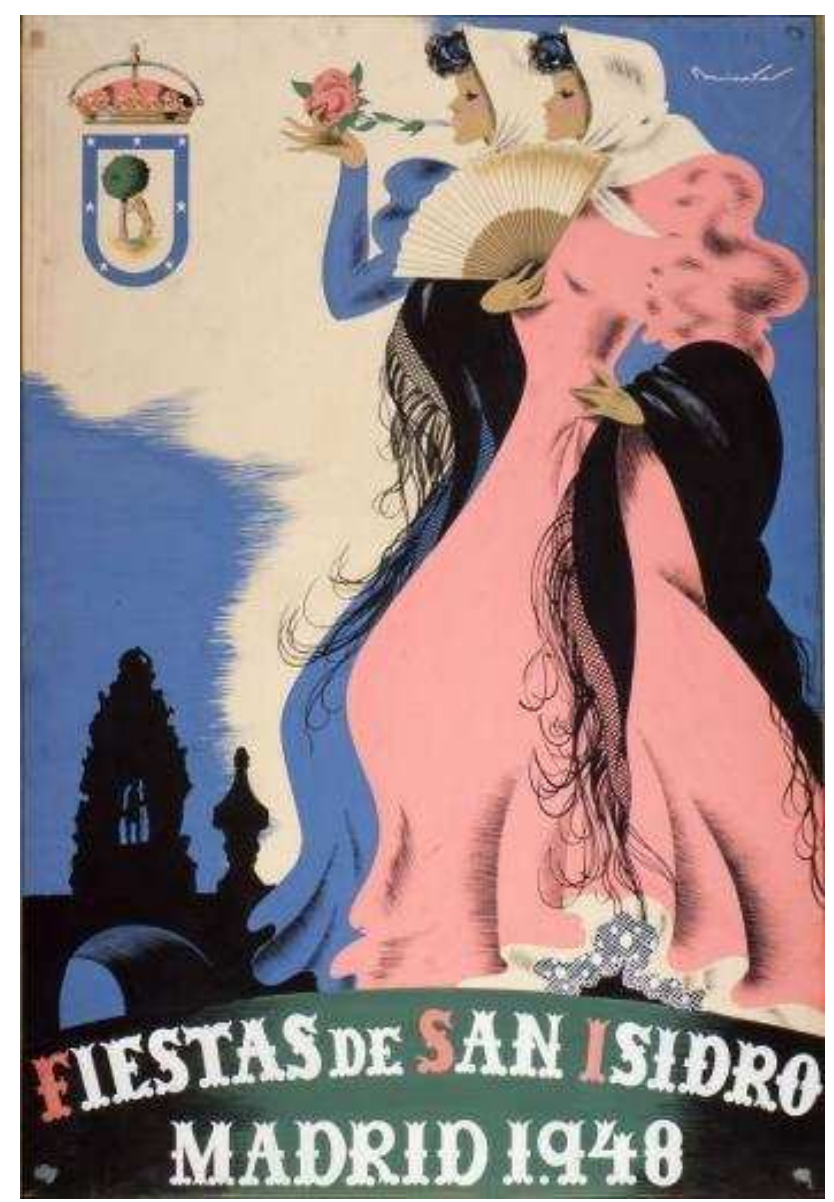

\begin{tabular}{|l|l|}
\hline \multicolumn{2}{|l|}{ Análisis Formal } \\
\hline $\mathrm{N}^{\text {R }}$ Registro & 02 \\
\hline Centro & Museo de Historia de Madrid (Inv. 23537) \\
\hline Lugar & Madrid \\
\hline $\begin{array}{l}\text { Título } \\
\text { atribuido }\end{array}$ & Fiestas de San Isidro de 1948 \\
\hline Datación & 1948 \\
\hline Autor & Pedro Mairata Serrano \\
\hline Firma & Sí, esquina superior derecha. Firma como 'Mairata'. \\
\hline Editor & - \\
\hline Dimensiones & 110 x 79 cm. \\
\hline Soporte & Papel entretelado \\
\hline Técnica & Témpera \\
\hline Tintas & Color; cinco tintas. \\
\hline D.L. & - \\
\hline Análisis de Contenido \\
\hline Texto & FIESTAS DE SAN ISIDRO/ MADRID 1948 \\
\hline Imagen & $\begin{array}{l}\text { Ocupando la parte derecha y central la figura de dos chulapas con pañuelo, clavel, } \\
\text { abanico y mantón. En el ángulo inferior izquierdo, la silueta del Puente de Segovia } \\
\text { con la escultura del Santo. }\end{array}$ \\
\hline \multicolumn{2}{|l|}{$\begin{array}{l}\text { Abanico, Chulapas, Clavel, Escudo, Fiestas populares-San Isidro Labrador, Mantón, } \\
\text { Puente de Segovia-Madrid, San Isidro Labrador, Tipos populares madrileños }\end{array}$} \\
\hline Notas & Consta de lema: 'Rosa y la Trini' (en el bastidor). \\
\hline
\end{tabular}

Ejemplo 1. Cartel de fiestas. 


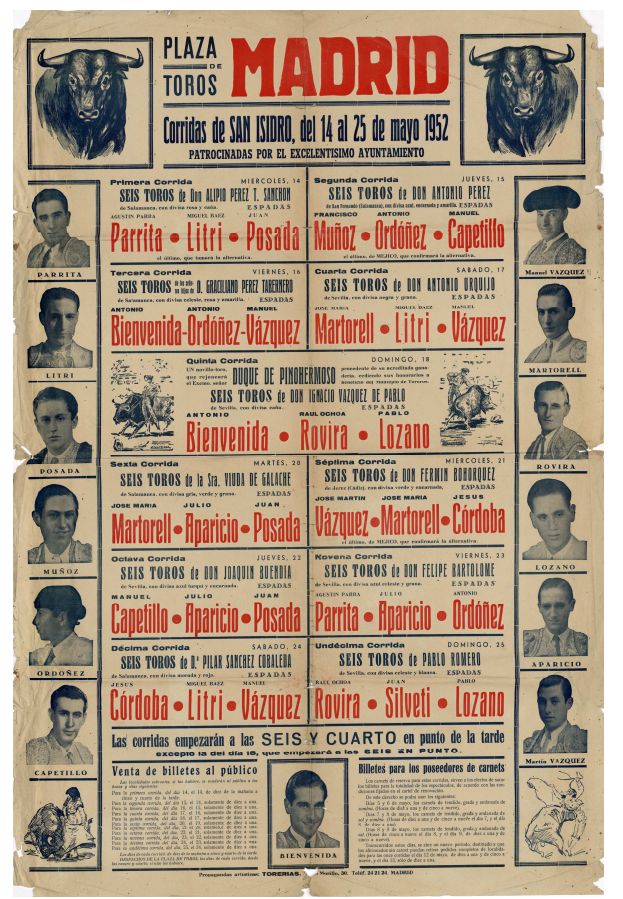

\begin{tabular}{|c|c|}
\hline \multicolumn{2}{|c|}{ Análisis Formal } \\
\hline No Registro & 43 \\
\hline Centro & $\begin{array}{l}\text { Biblioteca Nacional de España (CART. P/427); Biblioteca Regional Joaquín Leguina de Madrid } \\
\text { (Mg. XXI-184) }\end{array}$ \\
\hline Lugar & Madrid \\
\hline Título & Feria de San Isidro de 1952 \\
\hline Datación & 1952 \\
\hline Autor & - \\
\hline Firma & - \\
\hline Editor & Torerías \\
\hline Dimensiones & $79 \times 55 \mathrm{~cm}$. \\
\hline Soporte & Papel \\
\hline Técnica & Tipografía \\
\hline Tintas & Color; dos tintas \\
\hline D.L. & - \\
\hline \multicolumn{2}{|c|}{ Análisis de Contenido } \\
\hline Texto & $\begin{array}{lcccccccccc}\text { PLAZA } & \text { DE TOROS/MADRID/Corrida de SAN ISIDRO, del } & 14 & \text { al } & 25 & \text { de } & \text { mayo } & \text { de } \\
\text { 1952/PATROCINADAS POR EL EXCELENTÍSIMO AYUNTAMIENTO } & & & & & & \\
\end{array}$ \\
\hline Imagen & $\begin{array}{l}\text { El programa de las corridas se enmarca en dos columnas laterales con retratos de los toreros } \\
\text { participantes. En la parte inferior, torero realizando pase de pecho frente al toro y esperándole. }\end{array}$ \\
\hline Programa & $\begin{array}{l}\text { Antonio BIENVENIDA; Antonio ORDÓÑEZ; Antonio PÉREZ DE SAN FERNANDO; Antonio } \\
\text { URQUIJO; DUQUE DE PINOHERMOSO; Felipe BARTOLOMÉ; Fermín BOHÓRQUEZ (Ganadería); } \\
\text { Francisco MÚNOOZ; GALACHE, Viuda de; Ignacio VAZQUEZ DE PABLO; Jesús CÓRDOBA; } \\
\text { Joaquín BUENDÍA; José María MARTORELL; José Martín VÁZQUEZ; Juan POSADA; Juan } \\
\text { SILVETI; Julio APARICIO; 'LITRI', (Miguel BÁEZ); Manolo VÁZQUEZ; Manuel CAPETILLO; } \\
\text { Pablo LOZANO; 'PARRITA', (Agustín PARRA); Raúl OCHOA RIVERA. }\end{array}$ \\
\hline Descriptores & $\begin{array}{l}\text { Pase de pecho; Retratos; San Isidro-Feria; Toreros; Toros } \\
\text { Antonio BIENVENIDA; Antonio ORDÓNEZ; Antonio PÉREZ DE SAN FERNANDO; Antonio } \\
\text { URQUIJO; DUQUE DE PINOHERMOSO; Felipe BARTOLOMÉ; Fermín BOHÓRQUEZ (Ganadería); } \\
\text { Francisco MÚNOZ; GALACHE, Viuda de; Ignacio VAZQUEZ DE PABLO; Jesús CÓRDOBA; } \\
\text { Joaquín BUENDÍA; José María MARTORELL; José Martín VÁZQUEZ; Juan POSADA; Juan } \\
\text { SILVETI; Julio APARICIO; 'LITRI', (Miguel BÁEZ); Manolo VÁZQUEZ; Manuel CAPETILLO; } \\
\text { Pablo LOZANO; 'PARRITA', (Agustín PARRA); Raúl OCHOA RIVERA. }\end{array}$ \\
\hline
\end{tabular}

Ejemplo 2. Cartel taurino. 


\section{EL CARTEL EN ESPAÑA.}

El cartel más antiguo de España del que se tiene noticia, está fechado en 1737 en Madrid y se trata de un cartel tipográfico que anunciaba la celebración de una corrida de toros. De 1761 data otro cartel taurino en Sevilla que hasta hace poco tiempo se había considerado pionero. Estos primeros carteles eran más bien avisos realizados a partir de frases hechas que informaban de la celebración del espectáculo.

Junto a estos primeros carteles de temática taurina, de 1830 data un cartel litográfico El café de las siete puertas de Barcelona, redactado en tres idiomas y precursor del cartel publicitario de carácter comercial. Pero será en 1875 cuando aparezca el que se ha considerado primer cartel comercial español, Los Gordos y los Flacos, obra de Francisco Ortego Vereda.

En el desarrollo del cartel publicitario en España serán claves la llegada de la litografía en color así como la influencia de los maestros franceses como Chéret o Lautrec. La demanda creciente del cartel publicitario favorecerá la especialización del oficio y el desarrollo del género durante el último cuarto del siglo XIX y la primera parte del siglo XX en España (Eguizábal, 1998, p. 461). Figura destacada será Marcelino Unceta, que dotará al cartel de sentido estético, además del valor funcional que le dio origen. Su primer cartel data de 1879 y es de temática taurina, convirtiéndose en un gran maestro de este registro.

Desde finales del siglo XIX el cartel se va haciendo un hueco en la sociedad de consumo y cada vez son más los eventos y entretenimientos de la época que se anuncian en este soporte como los bailes, los cafés, las fiestas populares, así como empresas y comercios, especialmente los productores de bebidas, aguardientes y manzanillas. Pero el impulso definitivo del cartel llegaría con el modernismo y su interés por las artes gráficas así como con la organización de concursos de carteles por parte de instituciones y empresas de distinta naturaleza. Con estas iniciativas las empresas buscaban nuevas ideas y diseños únicos en artistas y dibujantes, alejándose de las agencias de publicidad, más encorsetadas ${ }^{1}$. El primer concurso fue convocado por Vicente Bosch en 1897 para el lanzamiento del Anís del Mono en una nueva botella en forma de frasco de perfume. Los premios eran de $1.000,500$ y 250 pesetas. Se presentaron 172 carteles resultando ganador Ramón Casas (Quintas, 2008, p. 4). A este concurso, le seguirían otros como el de los cavas Codorniú, la perfumería Gal o la revista Blanco y Negro.

A medida que avanza el siglo el cartel como soporte publicitario va ganando terreno. El deseo de viajar ha estado presente en todas las épocas, aunque los destinos han ido cambiando con las modas y el desarrollo de los medios de transporte. En los años 30, en algunos países como España la industria turística constituye una de las principales bazas de la economía, por lo que se realizaron campañas de difusión por parte del Patronato Nacional de Turismo para promocionar los encantos de España y sus fiestas. De este modo se sentaban las bases para el nacimiento de los flujos turísticos, una de las principales fuentes de riqueza y empleo en nuestro país durante las décadas posteriores, e incluso en la actualidad.

Un hito destacado en la producción cartelística de nuestro país será la Exposición Universal en Barcelona y la Iberoamericana en Sevilla, ambas celebradas en 1929. Para tales acontecimientos no se dudó en encargar a los pintores más destacados de la época libros, folletos y carteles para promocionar España. Esta circunstancia atrajo a Madrid y Barcelona numerosos creativos como Manuel Prieto -creador del Toro de Osborne- o Lorenzo Goñi, cartelista republicano que se instala en Barcelona. Y es que desde 1910, publicitar en España ha sido una actividad en la que han colaborado instituciones y artistas que ha dado como resultado una colección de imágenes del patrimonio español en carteles de importantes pintores de las primeras décadas del siglo XX. Nombres destacados serán Rafael de Penagos creador de la ilustración Art Déco en España- o el muralista valenciano Josep Renau.

La Guerra Civil divide el país y la publicidad y el cartelismo adoptan un marcado sentimiento patriótico, caracterizado por la agresividad de los mensajes y el anonimato de sus creadores. Finalizada la guerra, el orgullo de lo nacional se refleja en la publicidad y en las creaciones de los artistas, que trabajan bajo las premisas del régimen franquista. El periodo de posguerra no será propicio para las innovaciones siendo la repetición de modelos y diseños la tendencia generalizada.

La industria publicitaria conseguirá mantenerse gracias a las iniciativas y concursos organizados por instituciones como la Cruz Roja, el Patronato Nacional de Turismo y la Ciudad Universitaria, para su Lotería, y el Ayuntamiento de Madrid, en honor a las fiestas de su patrón, San Isidro Labrador. 
El desarrollo industrial y el auge del turismo de los años 60 supone un impulso para la publicidad, sobre todo la exterior con la cadena de vallas Red, creada en 1962, y que será una contribución clave en la industria publicitaria española. La valla publicitaria es consecuencia de la llegada del automóvil, y por tanto, dirigida a una población que se mueve en vehículo y no puede detenerse ante ningún mensaje, que era fundamentalmente una imagen. La técnica fotográfica será la dominante, especialmente en los años setenta. A partir de la transición, el vídeo, la televisión y el cine serán los nuevos medios que ofrezcan soporte a la publicidad. La búsqueda de una nueva imagen del cartel, con diseños e ideas de mayor impacto, llevará a la industria a buscar la colaboración de creativos y artistas de renombre, tendencia que se ha seguido desde los años ochenta.

\subsection{Estructura y diseño.}

La singularidad del cartel reside más en las características del soporte que en las del mensaje, que puede ser muy variado tanto por los objetivos o por el tipo de códigos que utilice. De carácter efímero, utiliza un soporte de dos dimensiones y de naturaleza frágil, siendo los más comunes el papel, cartón, tela o lienzo.

Si atendemos al tamaño, podemos señalar que ha sido variable a lo largo del tiempo. En España el formato normalizado partía de la doble marca mayor $(65 \times 90 \mathrm{~cm}$ aproximadamente), que a su vez podía dividirse en tamaños menores como la marca mayor $(65 \times 45 \mathrm{~cm})$ o bien, conseguir un cartel de mayor tamaño pegando varias hojas. Con frecuencia, el cartel se imprimía en varios formatos, sin embargo desde finales del siglo XIX el auge del coleccionismo favoreció la impresión de tiradas en formatos más manejables, como los programas de mano (de tamaño variable, entre $10 \times 15$ y 24×28 cm.) así como reproducciones a menor escala en otro tipo de productos de difusión como las invitaciones o las entradas.

En cuanto al diseño podemos identificar dos estilos, por un lado el cartel tipográfico conformado exclusivamente por texto, correspondiente a los primeros años del cartel publicitario. Por otro, el cartel moderno en el que el diseño y lo icónico tienen un mayor protagonismo, haciendo alusión a aquello de una imagen vale más que mil palabras.

Con mayor o menor acierto, varias son las clasificaciones que se han aplicado a los carteles. Müller-Brockmann (1971) propone una tipología basada en cuestiones artísticas y funcionales estableciendo como categorías el cartel ilustrado, el cartel objetivo-informativo, el cartel constructivista y el cartel experimental, criterios que en ocasiones resultan ambiguos en su aplicación práctica.

Otra clasificación del cartel es la propuesta por Eguizábal en el estudio introductorio al catálogo Memoria de la seducción: carteles del siglo XIX en la Biblioteca Nacional (2002) que atiende a los criterios: tecnológico, referido a la técnica de reproducción (xilografía, tipografía, litografía y offset); estético, que contempla a su vez ejemplares de valor artístico y aquellos con valor puramente antropológico; según las características del emisor, diferenciado entre privados (fabricantes de bienes, espectáculos, editoriales, servicios...), públicos (gobiernos y administraciones) y mixtos (partidos políticos o asociaciones sin ánimo de lucro); y de contenido, diferenciando entre carteles propagandísticos y publicitarios. Desde el punto de vista del contenido, se establece una clasificación temática que responde a las diferentes actividades anunciadas en los carteles, estableciendo las siguientes categorías: carteles de circo, de teatro, taurinos, ferias, fiestas y exposiciones, viajes y transportes, mercancías, carreras de caballos, publicaciones, bailes, políticos y otros como los carteles de loterías y de turismo.

\section{EL CARTEL DE FIESTAS. ELEMENTOS CONSTITUTIVOS.}

Las celebraciones de las festividades unifican lo profano con lo religioso, lo popular con lo distinguido, siendo visible esta característica en el cartel de fiestas. El precursor del cartel de fiestas moderno lo encontramos en el pregón de fiestas cuya función es la de informar sobre la celebración de bailes, fiestas o ferias organizadas por instituciones oficiales y ayuntamientos durante un determinado período de tiempo en una localidad o lugar concreto. Su mensaje es sencillo y directo, sin embargo, la simplicidad del mensaje no afecta al diseño compositivo, mucho más elaborado y en constante evolución.

Al realizar un recorrido por la historia del cartel se puede apreciar una evolución en la composición y disposición del texto de los carteles de fiestas. Los creados antes de finales del siglo XIX son de carácter tipográfico, con un claro predominio de los elementos textuales sobre los icónicos. En ellos aparece la denominación de la actividad o festejo, se detalla el programa así como el nombre y cargo de las autoridades convocantes, a menudo destacadas tipográficamente en el encabezamiento del cartel. Es frecuente además la decoración de las letras titulares, la presencia del escudo de la ciudad o localidad así como el empleo de orlas, guirnaldas y otros elementos ornamentales. 
Sin embargo, durante el último cuarto del siglo XIX, el diseño de los carteles de fiestas da un giro hacia lo icónico, incorporando muchos de los recursos estéticos que actualmente se mantienen en el cartel, como la utilización de tipos folklóricos estereotipados y el uso de elementos alusivos de tipo alegórico o histórico. Se caracterizan por una mayor libertad compositiva que se refleja en la creación de una iconografía particular para cada festividad y región, el empleo de símbolos y lugares significativos de las ciudades, así como de elementos alusivos al carácter festivo de estas actividades.

El procedimiento habitual para el diseño y creación de los carteles de fiestas era mediante encargo de las instituciones a un artista, o bien a través de concursos, reavivando la participación popular y la modernización de estilo. Ejemplos destacados son los concursos de carteles realizados en Pamplona para las fiestas de San Fermín, en Sevilla para las fiestas de la Primavera, en Granada para el Corpus, y en Madrid, para los bailes de Carnaval del Círculo de Bellas Artes o las fiestas de San Isidro Labrador.

\section{EL CARTEL TAURINO. ICONOGRAFÍA Y ESTILO.}

En un principio, el procedimiento empleado por las instituciones oficiales para el anuncio de los festejos fue el pregón que se daba en la plaza pública acompañado por clarines y timbales, posteriormente convertido en bando en la misma plaza de toros (Cossío, 1943). En este se anunciaba el programa y una serie de advertencias referidas al orden y al mantenimiento de la tranquilidad pública durante el espectáculo taurino y las sanciones dispuestas para los perturbadores. Esta parte pasaría en forma de precepto a los carteles de toros.

El pregón callejero y el bando en la plaza quedarían en un segundo plano con la aparición del cartel, considerado inicialmente como instrucción para los interesados y espectadores, para convertirse después en el principal instrumento de propaganda de la fiesta de los toros. Su principal función es informar e ilustrar, empleando para ello la combinación de texto e imagen. Al igual que cualquier otra actividad comercial, con la publicidad del espectáculo los empresarios taurinos también persiguen otro objetivo, lograr beneficios económicos.

Aunque no es segura la fecha del primer cartel de toros, el más antiguo del que se tiene constancia está fechado en 1737 en la plaza de Madrid ${ }^{2}$. Se trata de un cartel anunciador de un festejo taurino los días 19 y 29 de septiembre en la plaza del Soto de Luzón. En los orígenes del género también va a tener una mención destacada la plaza de la Real Maestranza de Sevilla, donde aparece un cartel de toros en 1761. Estos primeros carteles de estética muy rudimentaria, se limitaban a anunciar con variada tipografía la fecha y lugar de las corridas, los diestros y las ganaderías. Después irían incluyendo preceptos y advertencias para el buen desarrollo de la fiesta -como la prohibición de arrojar al ruedo cáscaras de naranja, piedras, palos o animales muertos- constituyendo el primer intento de reglamento taurino.

Autores como Zaldívar (1990) establecen una línea divisoria en el estudio del cartel taurino. Por un lado, los carteles del siglo XVIII, obras anónimas dotadas de una gran simplicidad basada en la ornamentación tipográfica. Y por otro, los carteles del siglo XIX, ilustrados, a color, con escenas y tipos pertenecientes a la fiesta y firmados por el autor. Señala Santos Torroella (1949), que a partir del siglo XIX los carteles van ganando en complejidad ornamental que va del neoclasicismo a los motivos góticos y un mayor enriquecimiento de la tipografía. También modificarán su tamaño, pasando de una forma rectangular y apaisada a un formato alargado y vertical. Se aprecia una mayor libertad compositiva pasando de las flores y lazos del romanticismo al tema arquitectónico y a las orlas con alusiones a la fiesta (castoreños, sillas de montar, estribos, rehiletes, muletas, estoques, etc.) hasta llegar al cartel realista que conocemos hoy.

En definitiva, el cartel va a ir evolucionando de forma paralela al espectáculo taurino, adoptando distintos estilos y formatos: con retratos de toreros (principalmente en provincias), de forma circular, (poco frecuente pero muy vistoso), se amplían las imágenes que aparecen en las viñetas, también aparece el paseíllo, la manada en el campo y pasajes de la lidia (Zaldívar, 1990).

El descubrimiento y la adopción del fotograbado marcarán una nueva etapa en el cartel de toros. Será entonces cuando aparezcan las primeras casas especializadas, como la de Portabella en Zaragoza, la de Ortega en Valencia y las de Julián Palacios y Regino Velasco en Madrid. También empezarán a ofrecer su colaboración pintores especializados en el género como Marcelino Unceta, los hermanos Perea (Alfredo y Daniel) y Francisco Ortego, colaboradores habituales de las revistas taurinas de la época como Sol y Sombra, La Lidia ${ }^{3}$ o El Chiquero (Zaldívar, 1990). Para las corridas reales o de beneficencia colaboraron en el cartel artistas de la talla de Benlliure y Sorolla. 
A partir de 1930 el cartel de toros experimenta una ligera apertura hacia el exterior, quizás debido a la aparición de los concursos dentro de este género destacando el concurso organizado por el crítico de arte Gil Fillol para la corrida de la Prensa en 1936 (previo a la contienda), en Pamplona (no sólo referidos a los toros sino también para anunciar el resto de los festejos), o la convocatoria anual que inicia en 1954 la Diputación Provincial de Madrid para la corrida de la Beneficencia ${ }^{4}$.

Tras la guerra el cartel taurino experimentará un declive tanto en la plástica como en los temas que se estereotipan y se vuelven reiterativos. Destacan sin embargo los trabajos de autores como Saavedra, Reus Parra y Rius y Cros Estrems autores de gran parte de los carteles de los años cincuenta y sesenta y otros artistas ocasionales como Mariano Benlliure, Lizcano, Picasso y Rafael Alberti.

La principal diferencia del cartel taurino con el mundo de las artes gráficas, es la falta de originalidad de sus fuentes y signos gráficos, con una reiteración de elementos y fórmulas dirigidas a un tipo de público muy específico, que entiende y conoce el espectáculo. Zaldívar (1990) señala como principales características el carácter realista de la plástica taurina; el empleo de una imagen sugestiva; la repetición de fórmulas y expresiones ("6-toros-6", "si el tiempo no lo impide", "las puertas de la plaza se abrirán dos horas antes", "una brillante banda de música amenizará el espectáculo", etc.); la presencia de dos líneas en el cartel -horizontal (el toro) y vertical (el torero)- y el entendimiento directo entre el emisor y el receptor.

De forma generalizada, existen dos tipos de composición: un primer tipo con motivos gráficos y orlas con dibujos y grabadillos de una gran variedad - propia de los primeros carteles- y un segundo tipo de mayor uniformidad, abocetado y con una composición similar a un cuadro. Los colores predominantes van a ser los rojos, amarillos y negros.

En función del tamaño y el lugar de difusión al que va destinado vamos a encontrar cinco modelos diferentes en la cartelería taurina: mural $(70 \times 150 \mathrm{~cm}$.), salón, escaparate $(26 \times 50 \mathrm{~cm}$.), de mano $(10 \mathrm{x} 15 \mathrm{~cm}$.) y de bolsillo $(7 \mathrm{x} 10$ cm.) (Zaldívar, 1990).

Si se analiza la iconografía presente en el cartel taurino en el siglo XIX el repertorio hace referencia a los siguientes motivos: cabezas de toros, instrumentos del toreo (picas, espadas, banderillas), toreros ataviados según la época, escenas de la lidia (paseíllo, banderillas, muleta, capote, cogida del caballo, escenas de campo, suerte final, tipos de toros, etc.). Otros temas y subtemas representativos serán el toro (triunfante, derrotado o en reposo), el torero, la mujer, los garrochistas, elementos frutales o los automóviles (Zaldívar, 1990). Todos estos elementos van a aparecer distribuidos en el cartel taurino que consta del nombre de la plaza, las fechas, las ganaderías y los toros a lidiar, los toreros, picadores y banderilleros, los precios, extracto del reglamento, y en algunos casos la imprenta donde se realiza.

\section{LAS FIESTAS DE SAN ISIDRO. RESEÑA HISTÓRICA.}

La ermita y la fuente que dieron origen a la Romería de San Isidro se localizan en el lugar que ocupaba la antigua casa de labor del santo en las tierras de los Vargas, espacio comprendido desde la Casa de Campo hasta el pueblo de Carabanchel. Ya en la Edad Media, se conoce de la existencia de una pequeña capilla junto a la fuente que los vecinos de Madrid llamaban de Isidro. En 1528, tras la curación milagrosa del Emperador y su hijo Felipe de unas fiebres con el agua de la fuente, la emperatriz Isabel de Portugal ordena la construcción de una ermita más grande, conservando sus materiales arquitectónicos y decorativos. A finales del siglo XVI fue ampliada por iniciativa de Juan de Frutos y costeada por limosnas, finalizando las obras en 1606. En 1724 se reedifica la ermita y es inaugurada el 11 de mayo de 1725 con fiestas varias. Es la ermita inmortalizada por Francisco de Goya en sus famosas obras. Durante la Guerra Civil es destruida y se vuelve a construir con la misma estructura. En la fachada del lado norte de la ermita, está la fuente de San Isidro, que viene de un manantial que nace en el cementerio del mismo nombre. A partir de este manantial, se construye un viaje de aguas medievales documentado en 1407, que llega hasta la fuente del Puente de Toledo, que acoge una escultura del santo patrón.

Los primeros datos sobre la celebración que se conocen datan de 1577, año en que la Archicofradía Sacramental de San Andrés acordó dar una colación de caridad en la ermita, después de haber celebrado la Santa Misa. En 1607, el cabildo de esta Archicofradía se reúne y acuerda la celebración anual en la ermita, fijándose la fecha en el 6 de mayo, día en el que se juntan en la ermita con los labradores que proceden de Carabanchel en otra procesión a la que concurren las cofradias de la parroquia de San Sebastián de Carabanchel (Puñal y Sánchez, 2000, p. 127). Sin embargo fue en 1620 cuando se instauró como fecha oficial del festejo el día 15 de mayo, y se conoce que el propio 
Felipe IV estuvo presente en la Romería en 1623 (Puñal y Sánchez, 2000). Para acortar el camino entre la iglesia de San Andrés y la ermita de San Isidro, la Archicofradía Sacramental construyó en 1633 un pequeño puente (donde actualmente se encuentra el Puente de San Isidro), con frecuencia destruido por las avenidas del río y sustituido después por un pontón, que dará origen a la actual denominación de Paseo de los Pontones.

En el siglo XIX, durante los días que se festejaba al santo, se llegaron a calcular 15.000 visitas (García Valcárcel y Écija, 1997) donde se daban cita bandas de música, había concursos, fuegos artificiales, bailes y la tradicional venta de productos típicos como los botijos o las rosquillas de la Tía Javiera.

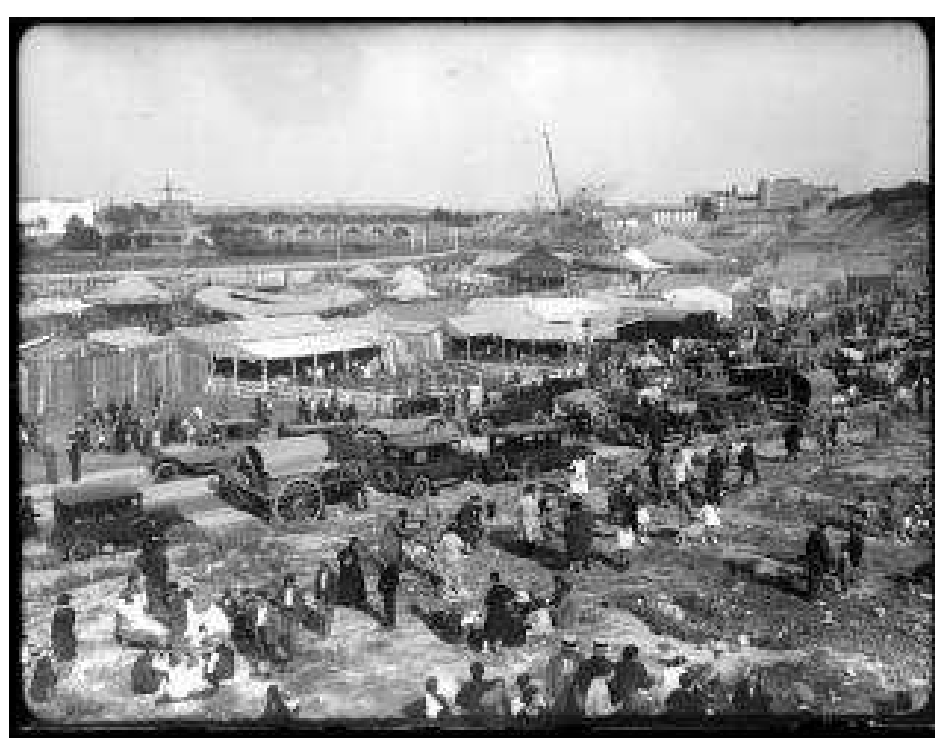

Figura 1. Fiestas en la Pradera de San Isidro en 1929. Gerardo Contreras. Negativo sobre cristal. (Museo de Historia de Madrid).

En un texto publicado en El Heraldo el 12 de mayo de 1846, se hace mención a la organización y puesta en escena de estos emplazamientos: "Han empezado ya los preparativos en las inmediaciones de San Isidro para la famosa romería. Los pobres de San Bernardino tienen colocadas sus hileras de cajones para las confiterías y venta de licores. El tio Vivo ha tomado ya puesto, y en todo el día de hoy quedará corriente el columpio y juego de caballos. En la pradera no se ve otra cosa que puestos de buñuelos que transcienden a aceite frito".

Tras los fusilamientos llevados a cabo durante la Guerra Civil en las tapias del cementerio de San Isidro, se consideró inapropiado el lugar para las celebraciones, trasladándose la fiesta a la Casa de Campo. Tras un breve período, volverá a su emplazamiento original, con un programa en el que se mezcla lo pagano y lo religioso.

La Romería de San Isidro actualmente se celebra en la pradera de San Isidro, espacio delimitado por los paseos de San Illán, Quince de Mayo, el paseo de la Ermita del Santo y la calle del General Ricardos. Las fiestas empiezan con el pregón, seguido de actuaciones musicales y verbenas en la pradera de San Isidro, la plaza de las Vistillas o la plaza Mayor. Los actos religiosos empiezan el domingo previo mediante la bendición del agua de la fuente del Santo. Estos actos culminan el 15 de mayo por la mañana en la explanada de la ermita en la pradera, clausurándose el domingo siguiente con el canto del 'Regina Coeli' a la Virgen. A la par, en la Colegiata de San Isidro, los actos empiezan seis días antes de la festividad del santo con la celebración vespertina de la eucaristía y quinario. El 15 de mayo por la mañana se realiza la misa de pontifical, acudiendo los madrileños y visitantes a venerar la reliquia del santo y visitar el camerín durante estos días.

\subsection{El concurso de carteles.}

Cada año, las fiestas eran presentadas al público mediante una serie de carteles que se colocaban en distintas zonas de la localidad, pero no será hasta 1947 cuando se inicie el concurso de carteles. Concretamente el 14 de marzo, el Ayuntamiento de Madrid publica la intención de celebrar, con sujeción a las bases que a continuación se expresan, un concurso del cartel anunciador de la festividad de San Isidro Labrador, Patrón de Madrid, para el corriente año, en el deseo de Ayuntamiento de procurar dar mayor realce cada año a dichas fiestas, repartiendo dicho cartel, una vez adjudicado e impreso por Artes gráficas Municipales, a todos los Ayuntamientos de España... ${ }^{5}$. Se expresa además la única concesión de un premio valorado en 5.000 pesetas y el derecho del jurado, formado por el Alcalde y los 
concejales de la Comisión de Deportes y Festejos, a declarar desierto el concurso. El motivo será libre y deberá presentarse bajo lema, a elección del propio artista.

El primer ganador del concurso será el artista Tadeo Villalba con su cartel 'Tres Cruces'. Sin embargo, en el acta de resolución también se contemplan dos premios más: un segundo para Ricardo Summers y un tercero para Enrique Azcona. A partir de la siguiente edición, y hasta 1967, las bases de las convocatorias recogen premios, quedando desierto en contadas excepciones.

La evolución de las bases del concurso, se conocen, en parte, gracias a su publicación en diferentes periódicos estatales, tales como ABC o El País, y sus hemerotecas. Así podemos comprobar cómo han variado elementos clave como el tamaño, la dotación del premio o las técnicas de creación de la pieza original.
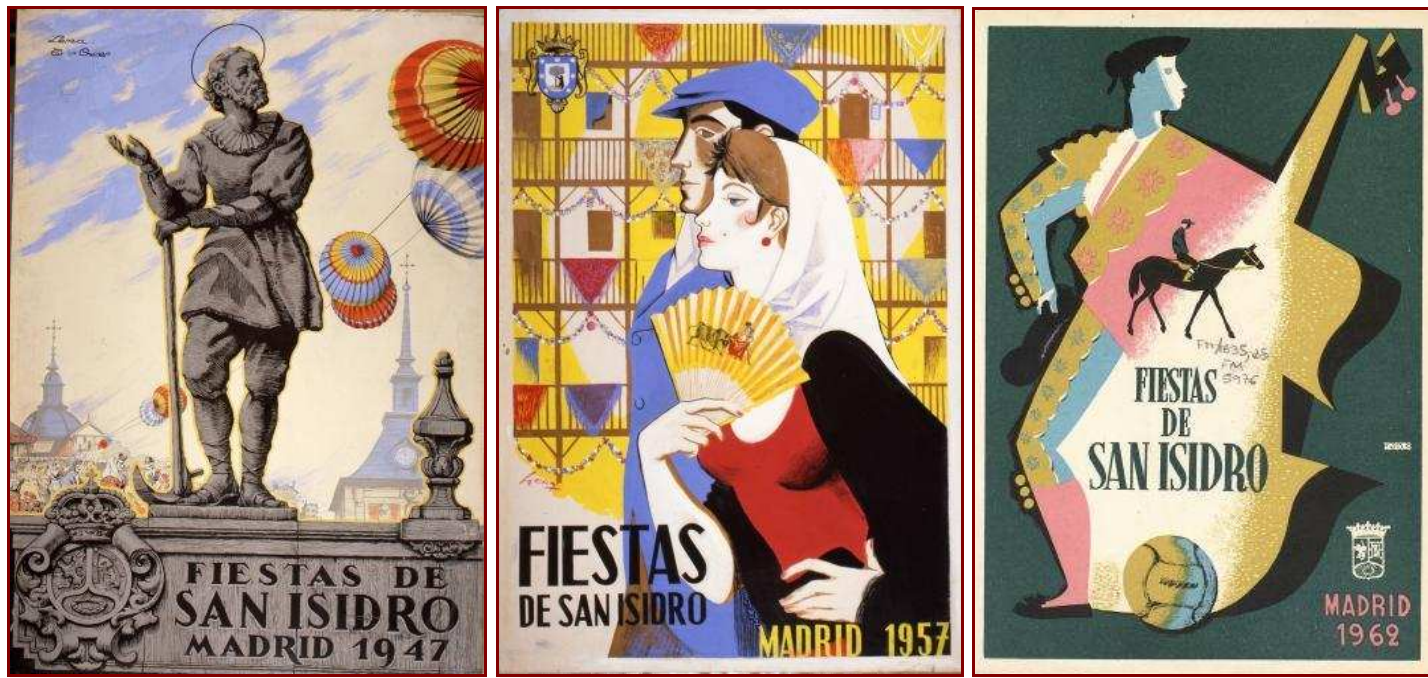

Figura 2. Carteles ganadores de las Fiestas de San Isidro firmados por Tadeo Villalba (1947), Ricardo Summers Ysern "Serny" (1957) y Teodoro Delgado (1962). Biblioteca Regional Joaquín Leguina de Madrid.

En 1951 se incluye en el jurado a un representante de la Real Academia de Bellas Artes de San Fernando, además de incluir como requisito indispensable la firma del autor y la supresión del lema. En cuanto a la técnica, en 1953 se indica que el artista, que ha de ser nacional, sólo debe utilizar cuatro tintas como máximo y sin aerógrafo. Se requiere además que las medidas del cartel sean de $65 \times 95 \mathrm{~cm}$ sobre bastidor, dimensiones que se mantendrán hasta la edición de 1983, donde las medidas serán de 98 x $68 \mathrm{~cm}$.

A partir de los primeros años de la década de los sesenta, el jurado se diversificará con un mayor número de especialistas y se descartan y prohíben los carteles no realizados por el autor en su totalidad o que contengan fotomontajes $^{6}$. En 1970, se aumenta a cinco tintas el máximo mientras que se mantiene la ausencia de aerógrafo, manteniéndose durante toda la década. En 1983 se publica que no existe limitación alguna de colores. A partir de 1985, dejará de realizarse el concurso en favor de la adjudicación del cartel a empresas gráficas y de diseño seleccionadas por el propio Ayuntamiento debido a la 'disminución del nivel' presentado en los últimos años ${ }^{7}$.

Pese a los cambios producidos en la técnica o las medidas, la creación de los carteles al dictado de las bases del concurso permite afirmar que existe cierta homogeneización en sus características. El escudo de la capital junto con la leyenda indicativa de la celebración de las fiestas y el año, son los dos temas fijos del cartel de fiestas de San Isidro. 

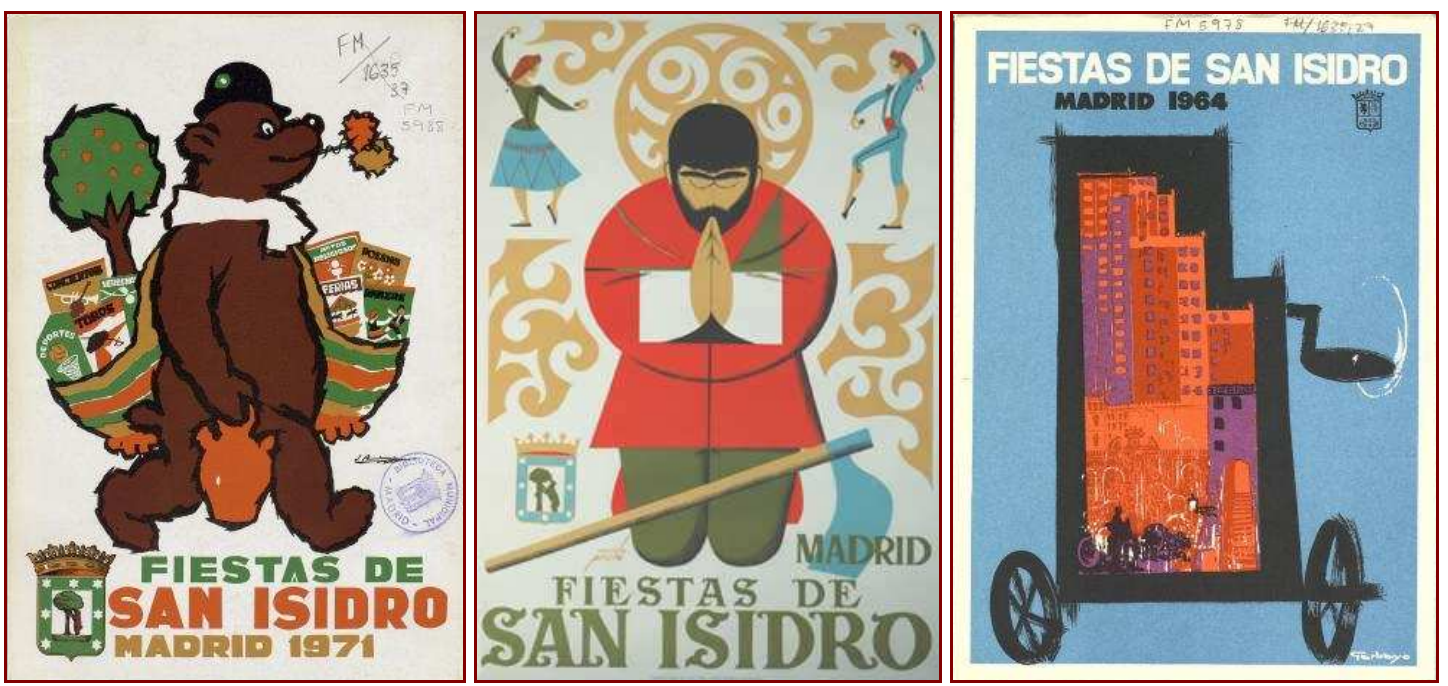

Figura 3. Carteles ganadores de las Fiestas de San Isidro de Madrid firmados por Fermín Hernández Garbayo (1964), Manuel Prieto Benítez (1969) y José Barahona Marco (1971). Biblioteca Regional Joaquín Leguina de Madrid.

Junto a estos, destacan otros temas también presentes en estos carteles como los escenarios urbanos y lugares significativos como la pradera de San Isidro o la fuente de la Cibeles; el folklore madrileño, representado por tipos tradicionales como la figura del oso, los manolos, chulapos y goyescos y elementos de su vestimenta (claveles, pañuelos blancos, etc.); la fiesta, representado en la verbena y la música y otras actividades vinculadas como pueden ser los eventos deportivos o la feria taurina.

\subsection{La Feria Taurina de San Isidro.}

En 1947 se inicia la celebración de la Feria taurina de San Isidro en la Plaza de Toros de las Ventas. Madrid es una ciudad de tradición taurina muy arraigada, contando con un tipo característico de cartel desde sus inicios y con un calendario muy amplio. La Feria taurina de San Isidro, tal y como se conoce en la actualidad, tiene sus orígenes en 1947, momento en el que el empresario de origen belga Livino Stuyck sustituye en la gerencia de la Plaza de las Ventas a Alonso Orduña. Será Stuyck quien decida reunir bajo un mismo abono el conjunto de corridas que se venían realizando durante el mes de mayo bajo el nombre de Feria de Madrid, que años más tarde recibirán el definitivo nombre de Feria de San Isidro. También fue el encargado de retomar el tradicional abono, que había desaparecido con la irrupción de la Guerra Civil.

El 15 de mayo de 1947 se celebró la primera corrida de la feria, estando en cartel los diestros Rafael Ortega Gallito, Manuel Álvarez Andaluz, y Antonio Bienvenida. En un primer momento, la feria taurina sólo constaba de cinco corridas, que se fueron incrementando hasta llegar a las veintiocho que se celebran en la actualidad, concretamente veinticuatro corridas de toros, dos novilladas y dos de rejones. 

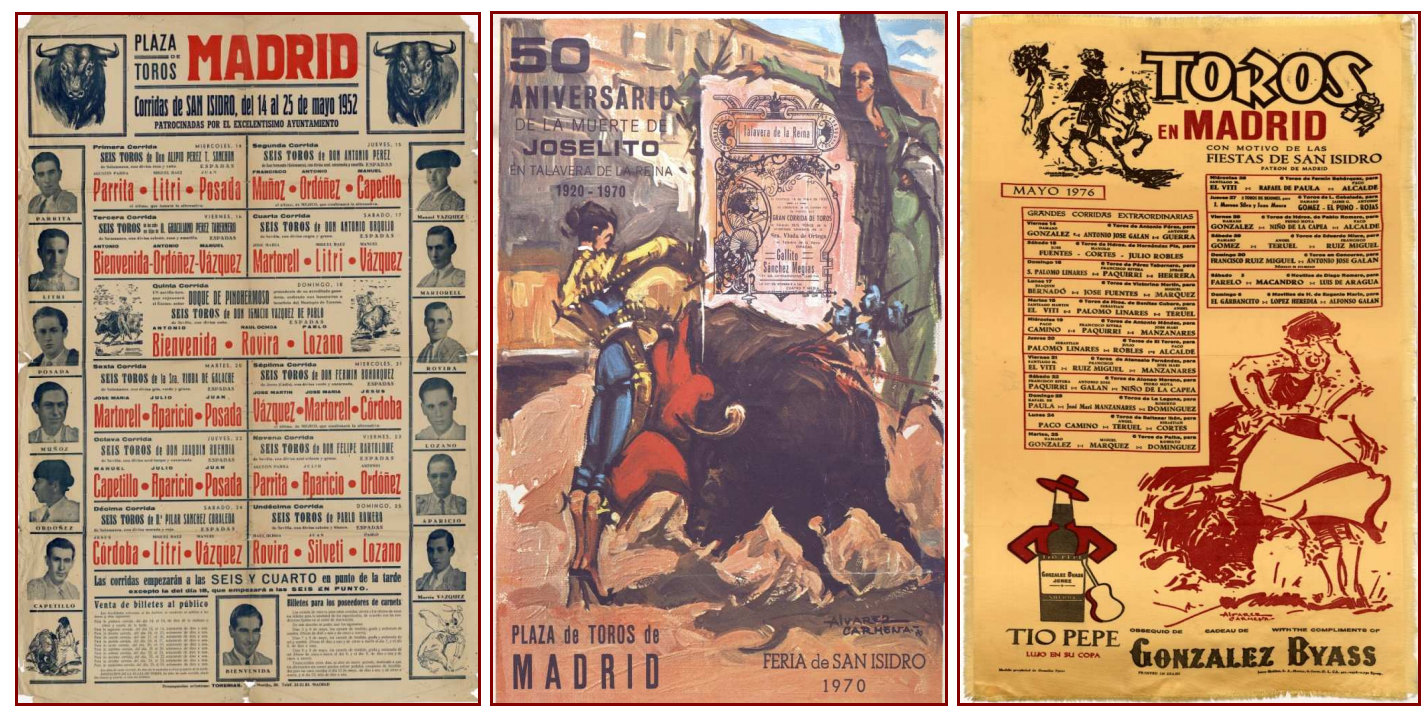

Figura 4. Carteles de la Feria taurina de San Isidro 1952-1970-1976. Museo de Historia de Madrid y Biblioteca Regional Joaquín Leguina de Madrid.

Desde el punto de vista iconográfico, los temas más frecuentes del cartel de la Feria taurina de San Isidro son el ruedo, representado con escenas de la lidia protagonizadas tanto por el torero, el rejoneador, el banderillero, el toro bravío y diversos pases de la faena, como el pase de pecho o el estatuario; el toro manso, con escenas de toros en el campo junto con los mayorales y la Plaza de las Ventas con su característica fachada neo-mudéjar, presente en más de un tercio de los carteles analizados.
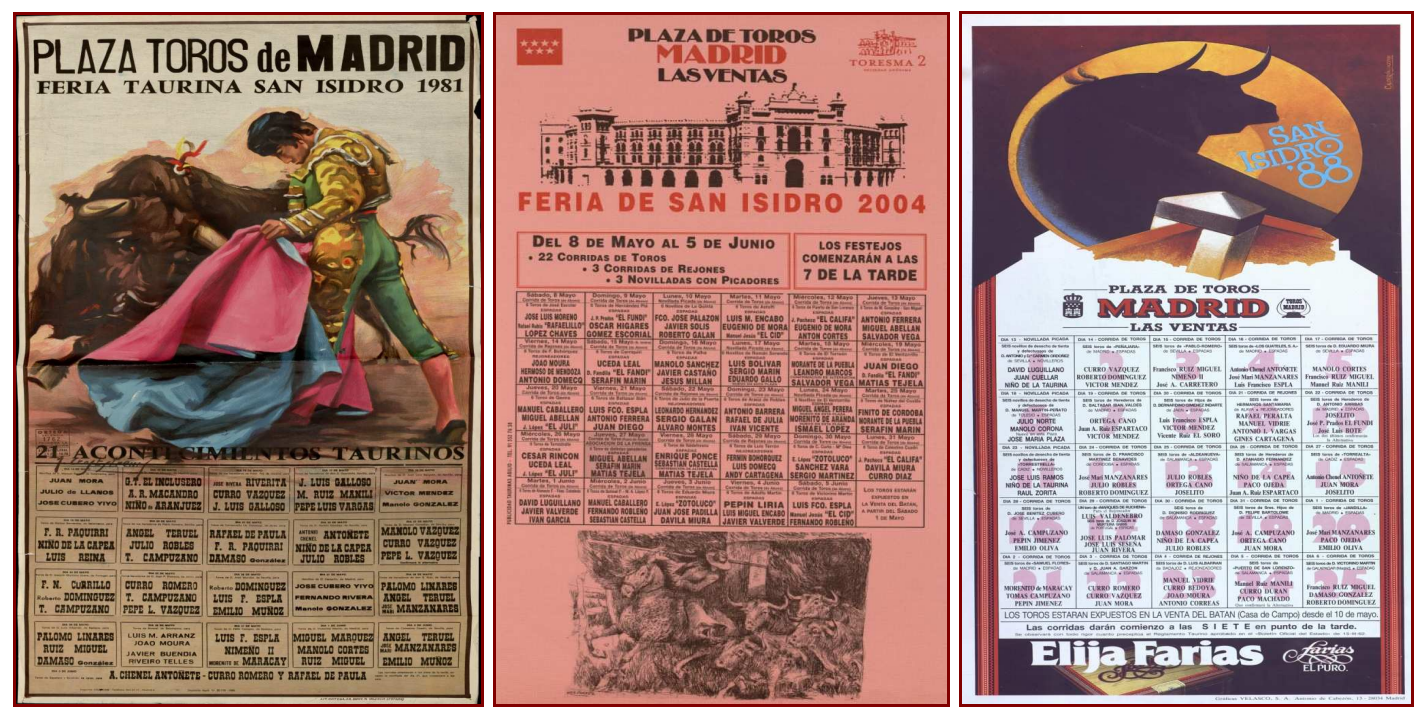

Figura 5. Carteles de la Feria taurina de San Isidro firmados por Cros Estrems (1981), Calderón Jacome (1988) y José Puente (2004). Biblioteca Regional Joaquín Leguina de Madrid.

\section{RESULTADOS.}

El modelo de análisis documental diseñado ha sido fundamental para la identificación, caracterización y localización de los 71 carteles de fiestas y taurinos que constituyen la muestra. La gestión de la información descriptiva mediante la base de datos diseñada para tal efecto, ha permitido realizar un análisis cuantitativo de la muestra atendiendo tanto a criterios formales -autoría, formatos, técnicas y soportes- como de contenido -elementos iconográficos, temas, personajes, lugares y representados- arrojando los siguientes resultados.

En cuanto a los carteles de fiesta, el análisis formal arroja como primer dato que el $100 \%$ de los carteles están firmados, por lo que es posible identificar a los artistas creadores del cartel. Esta circunstancia viene justificada por las características de los carteles de fiestas, creados a partir de un concurso, en cuyas bases se establece como requisito 
indispensable que el autor firme la obra. En este sentido, se ha podido observar una variada relación de autores y estilos en los carteles vencedores de cada edición, destacando sobre el resto de artistas Pedro Mairata Serrano (12\%) y Teodoro Delgado (9\%) seguidos por Agustín Blancovaras y José Paredes Jardiel, ambos con un 7\%. Mención especial merecen autores como Serny o Manolo Prieto, artistas de gran prestigio y reconocimiento, que fueron cada uno ganadores de una edición.

El formato más utilizado en el corpus analizado es $100 \times 70 \mathrm{~cm}(38 \%)$ seguido por $110 \times 80 \mathrm{~cm}(21 \%)$ y $95 \times 65$ (14\%). Al igual que la firma, los formatos empleados han venido determinados por las bases del concurso, que han establecido en cada momento las dimensiones admitidas para los carteles presentados a concurso.

La técnica más utilizada en el conjunto de carteles es la témpera, que representa un $83 \%$ del total de los carteles, seguido de la técnica fotomecánica, con un $12 \%$. Las menos utilizadas han sido el óleo, la serigrafía y el collage, representadas con un $2 \%$ cada una.

En cuanto al análisis de contenido se observa que el escudo heráldico de la villa ha sido un elemento constante en todos los carteles de fiesta creados desde 1947 hasta 1984. A partir de esa fecha, en la que desaparece la modalidad concursal, el escudo es sustituido por el "eslogan" del Ayuntamiento, que funciona como marca. No obstante hay otros temas que también han tenido una gran presencia en los carteles premiados.

Se comprueba que, de los 42 carteles analizados de la fiesta de San Isidro, los escenarios urbanos están presentes en un $42 \%$, las tradiciones madrileñas en un 57\% y las actividades lúdicas asociadas a la fiesta en un $76 \%$. En cuanto a los escenarios urbanos destacan la ermita de San Isidro (4\%), la fuente de la Cibeles (12\%), la plaza Mayor (4\%), la pradera de San Isidro (4\%) y la Torre de España (7\%). Las tradiciones vienen representadas en los carteles por los tipos populares madrileños como son los goyescos, los manolos y chulapos con un 57\%, el oso (19\%) y las corralas con un $2 \%$. También es muy frecuente encontrar en los carteles objetos y piezas de la indumentaria tradicional como el abanico (9\%), el bombín (7\%), el botijo (14\%), el clavel (14\%) o el mantón (12\%). En cuanto a la fiesta y las actividades lúdicas, las más destacadas son la música y el baile (58\%), la verbena (48\%), los toros (20\%), las atracciones de feria $(10 \%)$ y los deportes como el fútbol y la hípica también con un $10 \%$.

En cuanto a los carteles taurinos, podemos afirmar que un 17\% son de autor desconocido. Entre los autores destaca Álvarez Carmena, que firma un 55\% de los carteles estudiados y la presencia de artistas de gran reconocimiento en el arte del cartel taurino como Cros Estrems, con un $3 \%$. El formato más frecuente en el corpus analizado es de $52 \times 24 \mathrm{~cm}$. (51\%) y de $43 \times 24 \mathrm{~cm}(17 \%)$ y principalmente se trata de carteles de escaparate. La técnica más utilizada es el estampado sobre tela, presente en un 58\%, seguida de la tipografía (34\%) y la impresión offset $(3 \%)$.

Los temas más recurrentes en los carteles de la feria taurina son el ruedo (86\%) con la figura del torero (55\%), el rejoneador (24\%) o el banderillero (10\%) y el toro en el campo (31\%). La Plaza de las Ventas aparece representada en un $38 \%$ del total de los carteles. Destacar como curiosidad, la presencia de la ermita de San Isidro en el cartel de 1983 , vinculándose así la feria taurina con la fiesta popular.

Además del análisis cuantitativo de la muestra atendiendo a criterios cronológicos, temáticos, autoría, formatos, técnicas y soportes, la base de datos diseñada ha permitido la elaboración de diversos índices (temático, onomástico, geográfico, de artistas autores del cartel, de toreros y novilleros, de rejoneadores, y de ganaderías) para la búsqueda de elementos tanto iconográficos como textuales presentes en el conjunto de carteles analizados, así como un catálogoinventario para la identificación y localización de los carteles referidos a las fiestas de San Isidro y que se encuentran dispersos en distintos centros e instituciones. Este catálogo constituye una herramienta de referencia para futuros estudios e investigaciones sobre este género de carteles (Anexo I).

\section{CONCLUSIONES.}

1. En la iconografía del conjunto de carteles estudiado podemos identificar la ciudad de Madrid, la verbena, la romería y los festejos taurinos. Para representar la ciudad de Madrid, el oso y la Cibeles son los elementos iconográficos más utilizados. Para la verbena, los manolos, goyescos y chulapas, ataviadas con clavel, abanico y mantón, son los más recurrentes. Para representar la romería, la figura del santo, la pradera de San Isidro y el botijo. En cuanto a los carteles taurinos, el ruedo, el torero, el rejoneador, el toro en el campo y la fachada de la Plaza de las Ventas son los motivos más utilizados. 
2. La estructura clásica del cartel taurino se ha mantenido a lo largo de los años, tanto en la disposición del texto, como en los temas y escenas de lidia representadas en las ilustraciones, el torero y el toro. La principal diferencia de los carteles taurinos de Madrid con los carteles de las plazas de otras ciudades viene marcada en algunos casos en que aparece la fachada del coso madrileño de Las Ventas. En definitiva, los carteles taurinos analizados mantienen una estructura más homogénea y sin grandes cambios, tanto en la forma como en el contenido. En este sentido, en el corpus analizado ha permanecido casi invariable la disposición del texto 'FERIA DE SAN ISIDRO' seguido del año y, a continuación, el programa completo con todas las corridas, siendo de menor importancia los aspectos ornamentales y decorativos. Se observa además el uso del cartel taurino como depositario de informaciones ajenas al programa, como ocurre en los carteles-obsequio que ciertas marcas y empresas regalan como medio publicitario (Tío Pepe, González Byass, Farias, etc.). En cuanto a la autoría de las obras, se constata un alto porcentaje de carteles de autor desconocido. La figura que destaca sobre el resto es la de Álvarez Carmena, reafirmándose su valor y especialización en esta tipología de carteles, resultando de gran interés un estudio de su obra completa.

3. Pese a que los carteles de fiesta se han creado al dictado de las bases de los concursos, en el análisis de la muestra de carteles en el periodo comprendido entre 1947 y 2005 se percibe una mayor libertad en composición iconográfica así como en la distribución del texto, que no mantiene una estructura predeterminada, a diferencia de lo que ocurre en los carteles taurinos. Podemos afirmar, por tanto, que en el conjunto de carteles de fiestas estudiado las ilustraciones y los elementos gráficos tienen mucho más peso que los elementos tipográficos, y se refleja en el importante catálogo de iconos reconocibles para los ciudadanos que se han representado a lo largo del tiempo como la plaza Mayor o la fuente de Cibeles, la ermita del Santo y la pradera de San Isidro, escenarios y lugares vinculados con esta festividad, así como diferentes personajes de la historia y el folklore, como los chulapos, los goyescos, el oso y el madroño o Don Nicanor. El escudo heráldico de la villa ha sido un elemento constante en todos los carteles de fiesta creados desde 1947 hasta 1984, fecha en la es sustituido por el "eslogan" del Ayuntamiento, que funciona como marca. En cuanto a los autores de la cartelería, con más o menos acierto en su composición y ejecución, aparecen una interesante relación de artistas de renombre como Baldrich, Serny, Manolo Prieto u Óscar Mariné, así como otros artistas madrileños como Teodoro Delgado.

4. Para finalizar, destacar y reafirmar el valor e interés de los carteles de las fiestas patronales tanto en su vertiente religiosa como taurina desde varias perspectivas. En su dimensión gráfica, permiten apreciar la evolución del cartel como el principal medio de difusión de las fiestas, y las variantes que ha experimentado su formato y composición. En su dimensión artística, permite observar el influjo de las distintas corrientes en este soporte, su valor estético así como la obra de artistas gráficos relevantes. Y desde el punto de vista histórico nos permite recuperar una parte de nuestra historia, la evolución de las costumbres y tradiciones, escenarios de celebración y acontecimientos destacados. De especial interés resulta el cartel taurino para conocer los diferentes cosos taurinos, los precios, horarios, la evolución de los preceptos y normativa del espectáculo así como hechos destacados (alternativas, homenajes, conmemoraciones, etc.). En definitiva, el conjunto de carteles analizados se constituyen como un indicador del paso del tiempo respecto a la visión que los artistas y los ciudadanos tienen de Madrid y sus fiestas.

\section{Agradecimientos}

Destacar la ayuda prestada por parte de María Antonia Herradón Figueroa (Museo del Traje), Ángeles Díaz Sánchez, $\mathrm{M}^{\mathrm{a}}$ del Carmen García Calatayud y Amparo García Carrascosa (Biblioteca Nacional de España), Eva María Corrales Gómez y Purificación Nájera Colino (Museo de Historia de Madrid) y especialmente, a Belinda Yúfera Rodríguez (Biblioteca Regional Joaquín Leguina de Madrid).

\section{NOTAS}

\footnotetext{
${ }^{1}$ Cabe destacar la Unión de Dibujantes Españoles (UDE) creada en 1932, que funcionaba a modo de agencia de contratación. Cada mes celebraba el denominado Salón del Cartel Publicitario con los encargos y la entrega de premios al mejor. Esta iniciativa finalizará con la Guerra Civil.

${ }^{2}$ Expuesto en el catálogo oficial del Museo Municipal de mayo de 1959. № 30.

3 Daniel Perea confecciona un álbum con las estampas que se publicaban en esta revista.

4 Aunque esta celebración data de 1856 no será hasta 1952 cuando se convoque el primer concurso para el diseño de carteles de este festejo.

5 Boletín del Ayuntamiento de Madrid, n 2622, de 17 de marzo de 1947, p. 140

${ }^{6}$ Boletín del Ayuntamiento de Madrid, no 3391, de 22 de enero de 1962, p. 79.

${ }^{7}$ GARRIDO, M. Cómo organizar un concurso de carteles, en “Arte Comercial”, V, 1950, n’ 32 y 33, p. 18-31.REPASAR ESTA CITA
} 


\section{BIBLIOGRAFÍA.}

BARNICOAT, J. Los carteles: su historia y su lenguaje. Barcelona: Gustavo Gili, 1972.

BARRERA GARCÍA, A.I. Arte y artistas para la imagen de Sevilla y sus fiestas; el cartel y su función artísticopublicitaria. Laboratorio de Arte, 2012, n 24, p. 613-634.

BOUZA ÁlVAREZ, F. Procedimientos retóricos del cartel. Madrid: Centro de Investigaciones Sociológicas, 1983.

CABRERA BONET, R. Orígenes y evolución del cartel taurino en España. Sevilla: Consejería de Gobernación y Justicia, 2010.

CARNAVALES. COLECCIÓN DE CARTELES DEL CÍRCULO DE BELLAS ARTES. Madrid: Círculo de Bellas Artes, 1993.

CARTELES DE FIESTAS EN LA COLECCIÓN DEL MUSEO MUNICIPAL (1932-1991). Madrid: Museo Municipal, 1991.

CASTRO MORALES, F. Cartel, arte y patrimonio durante la guerra civil española: significación del cartel dentro del patrimonio cultural. PH: Boletín del Instituto Andaluz del Patrimonio Histórico, 1997, nº 18, p. 141-148.

CHECA GODOY, A. Historia de la publicidad. A Coruña: Netbiblo, 2007.

CORONADO E HIJÓN, D. La metáfora del espejo: teoría e historia del cartel publicitario. Sevilla: Alfar, 2001.

COSSÍO, J.M. de. Los toros: tratado técnico e histórico. Madrid: Espasa-Calpe, 1943.

EGUIZÁBAL MAZA, R. Historia de la publicidad. Madrid: Eresma \& Celeste, 1998.

ENEL, F. El cartel: lenguaje, funciones, retórica. Valencia: Fernando Torres, 1974.

GALÁN QUINTANILLA, M.A. Un medio de documentación para la historia de la publicidad: el cartel modernista. Documentación de las ciencias de la información, 1983, nº 7, p. 265-272.

GARCÍA RUESCAS, F. Historia de la publicidad y del arte comercial en España: desde tiempos remotos al final del siglo XX. Madrid: Arus, 2000.

GARCÍA VALCÁRCEL, R. y ÉCIJA, A. Ma . Fiestas tradicionales madrileñas. Ed. Madrid: La Librería, 1997.

LECHUGA, D. San Isidro: 50 ferias 50. Madrid: Alianza, 1997.

MEMORIA DE LA SEDUCCIÓN: CARTELES DEL SIGLO XIX EN LA BILIOTECA NACIONAL. Madrid: Biblioteca Nacional de España, 2002.

MONTOLIÚ CAMPS, P. Fiestas y tradiciones madrileñas. Madrid: Silex, 1990.

PLEGUEZUELOS RODRÍGUEZ, M.I. El cartel taurino, arte y pasión. Valencia: Aurom, 2006.

PUNAL, T. y SÁNCHEZ, J.Ma. San Isidro de Madrid, un trabajador universal. Madrid: La Librería, 2000.

QUINTAS FROUFE, E. Origen y proliferación de los concursos de carteles a principios del siglo XX: el concurso de la perfumería Gal (1916). Área Abierta, 2008, nº 21.

RENAU, J. Función social del cartel publicitario. Valencia: Nueva Cultura, 1937.

SANTOS TORROELLA, R. El Cartel. Barcelona: Argos, 1949.

TORRES GONZÁLEZ, B. El cartel taurino. Quites entre sol y sombra. Museo: Revista de la Asociación Profesional de Museólogos de España, 1998, nº 3, p. 198-207.

TORRES GONZÁLEZ, B. La tipografía del cartel taurino en el siglo XIX. Espacio, Tiempo y Forma. Serie VII, Historia del Arte, 2000, nº 13, p. 431-470.

TORRES GONZÁLEZ, B. Elementos decorativos en el cartel taurino. Espacio, Tiempo y Forma. Serie VII, Historia del Arte, 2001, no 14, p. 219-250.

TORRES GONZÁLEZ, B. El cartel taurino. Madrid: Dirección General de Archivos, Museos y Bibliotecas, 2006.

TRENC BALLESTER, E. El cartel festivo en la España de los años 20. Seminario de arte aragonés, 1999, $\mathrm{n}^{\circ}$ 48, p. 471-498.

ZALDÍVAR, R. El cartel taurino: historia y evolución de un género (1737-1990). Madrid: Espasa-Calpe, 1990. 


\section{ANEXO I. CATÁLOGO-INVENTARIO}

01

Fiestas de San Isidro de 1947

Tadeo Villalba

112 x $79 \mathrm{~cm}$. Papel entretelado. Témpera

Museo de Historia de Madrid (Inv. 23536)

02

Fiestas de San Isidro de 1948

Pedro Mairata Serrano

110 x $79 \mathrm{~cm}$. Papel entretelado. Témpera

Museo de Historia de Madrid (Inv. 23537)

03

Fiestas de San Isidro de 1949

Pedro Mairata Serrano

95 x $65 \mathrm{~cm}$. Papel entretelado. Témpera

Museo de Historia de Madrid (Inv. 23540)

04

Fiestas de San Isidro de 1951

Echanove y Limas

100 x $70 \mathrm{~cm}$. Papel. Témpera

Museo de Historia de Madrid (Inv. 23545)

05

Fiestas de San Isidro de 1952

Pedro Mairata Serrano

108 x $77 \mathrm{~cm}$. Papel entretelado. Témpera

Museo de Historia de Madrid (Inv. 23547)

06

Fiestas de San Isidro de 1953

Pedro Mairata Serrano

108 x $77 \mathrm{~cm}$. Papel. Témpera

Museo de Historia de Madrid (Inv. 23550)

07

Fiestas de San Isidro de 1954

José Paredes Jardiel

106 x $74 \mathrm{~cm}$. Papel. Témpera

Museo de Historia de Madrid (Inv. 23554)

08

Fiestas de San Isidro de 1955

José Paredes Jardiel

105 x $70 \mathrm{~cm}$. Papel. Témpera

Museo de Historia de Madrid (Inv. 23555)

09

Fiestas de San Isidro de 1956

Teodoro Delgado

95 x $65 \mathrm{~cm}$. Papel entretelado. Témpera

Museo de Historia de Madrid (Inv. 23558)
10

Fiestas de San Isidro de 1957

Ricardo Summers Ysern (Serny)

113 x $72 \mathrm{~cm}$. Papel entretelado. Témpera

Museo de Historia de Madrid (Inv. 23561)

11

Fiestas de San Isidro de 1958

Roberto M. Baldrich

100 x $70 \mathrm{~cm}$. Papel sobre táblex. Témpera

Biblioteca Nacional de España. Sede Alcalá de

Henares (AHC/3109)

Museo Municipal de Madrid (Inv. 23564)

12

Fiestas de San Isidro de 1959

José Paredes Jardiel

100 x $70 \mathrm{~cm}$. Papel. Témpera

Biblioteca Nacional de España. Sede Alcalá de Henares (AHC/3401)

Museo Municipal de Madrid (Inv. 23569)

13

Fiestas de San Isidro de 1960

Carlos Ballesteros y Víctor María Cortezo

100 x $70 \mathrm{~cm}$. Papel. Témpera

Museo del Traje (CE061576)

Museo de Historia de Madrid (Inv. 23571)

14

Fiestas de San Isidro de 1961

Teodoro Delgado

$100 \times 70 \mathrm{~cm}$. Papel entretelado. Témpera

Biblioteca Nacional de España. Sede Alcalá de Henares (AHC/5966)

Museo de Historia de Madrid (Inv. 23573)

15

Fiestas de San Isidro de 1962

Teodoro Delgado

$100 \times 70 \mathrm{~cm}$. Papel entretelado. Témpera

Biblioteca Nacional de España. Alcalá de Henares (AHC/7012)

Museo de Historia de Madrid (Inv. 23576)

16

Fiestas de San Isidro de 1963

Pedro Mairata Serrano

99 x $70 \mathrm{~cm}$. Papel entretelado. Témpera

Biblioteca Nacional de España. Alcalá de Henares (AHC/8744)

Museo de Historia de Madrid (Inv. 23581)

17

Fiestas de San Isidro de 1964

Fermín Hernández Garbayo 
95 x $65 \mathrm{~cm}$. Papel entretelado. Témpera

Museo de Historia de Madrid (Inv. 23581)

18

Fiestas de San Isidro de 1965

Teodoro Delgado

99 x $70 \mathrm{~cm}$. Papel entretelado. Témpera

Biblioteca Nacional de España. Alcalá de

Henares (AHC/25624)

Museo de Historia de Madrid (Inv. 23584)

19

Fiestas de San Isidro de 1967

José Esteban Matamala

108 x $77 \mathrm{~cm}$. Papel entretelado. Témpera

Museo de Historia de Madrid (Inv. 23589)

20

Fiestas de San Isidro de 1968

Francisco Nogueras Sanjurjo

104 x $74 \mathrm{~cm}$. Papel entretelado. Témpera

Museo de Historia de Madrid (Inv. 23591)

21

Fiestas de San Isidro de 1969

Manuel Prieto Benítez

111 x $76 \mathrm{~cm}$. Papel. Témpera

Museo de Historia de Madrid (Inv. 23592)

22

Fiestas de San Isidro de 1970

Agustín Blancovaras

103 x $73 \mathrm{~cm}$. Papel entretelado. Témpera

Museo de Historia de Madrid (Inv. 23594)

23

Fiestas de San Isidro de 1971

José Barahona Marco

100 x $70 \mathrm{~cm}$. Táblex. Témpera

Museo de Historia de Madrid (Inv. 23596)

24

Fiestas de San Isidro de 1972

Agustín Blancovaras

101 x $72 \mathrm{~cm}$. Papel entretelado. Témpera

Museo de Historia de Madrid (Inv. 23599)

25

Fiestas de San Isidro de 1973

Leo Anchóriz

112 x $83 \mathrm{~cm}$. Papel sobre táblex. Témpera

Museo de Historia de Madrid (Inv. 23601)

26

Fiestas de San Isidro de 1974

Agustín Blancovaras

105 x $74 \mathrm{~cm}$. Papel entretelado. Témpera

Museo del Traje (CE020636)

Museo de Historia de Madrid (Inv. 23602)
27

Fiestas de San Isidro de 1975

Juan Poza Tártalo

100 x $79 \mathrm{~cm}$. Papel sobre madera. Témpera

Museo de Historia de Madrid (Inv. 23605)

28

Fiestas de San Isidro de 1977

Julián Santamaría

106 x 77,5 cm. Papel entretelado. Témpera

Museo de Historia de Madrid (Inv. 23608)

29

Fiestas de San Isidro de 1978

Patricia Delmar

94,5 x 67,5 cm. Lienzo. Témpera

Museo de Historia de Madrid (Inv. 23609).

30

Fiestas de San Isidro de 1979

Urbano Martín Mangas

$100 \times 70 \mathrm{~cm}$. Papel sobre madera

Témpera, collage

Museo de Historia de Madrid (Inv. 23610)

31

Fiestas de San Isidro de 1980

Santiago Leria Pastor

101,5 x 71,5 cm. Papel sobre táblex.Témpera

Museo de Historia de Madrid (Inv. 23611)

32

Fiestas de San Isidro de 1981

Santiago Leria Pastor

111 x $75 \mathrm{~cm}$. Papel sobre táblex. Témpera

Museo de Historia de Madrid (Inv. 23612)

33

Fiesta de San Isidro de 1982

Ramón Polo Aparicio

100 x $70 \mathrm{~cm}$. Papel. Collage, témpera

Museo de Historia de Madrid (Inv. 23613)

34

Fiestas de San Isidro de 1983

Pedro Sánchez Cáceres

98 x $68 \mathrm{~cm}$. Papel sobre cartón. Témpera

Museo de Historia de Madrid (Inv. 23614)

35

Fiestas de San Isidro de 1984

Roberto Turégano

88,5 x $62 \mathrm{~cm}$. Papel. Fotomecánica

Museo de Historia de Madrid

36

Fiestas de San Isidro de 1985

Óscar Mariné Brandi y Carlos Serrano 
67 x 94,5 cm. Papel. Fotomecánica

Museo de Historia de Madrid

37

Fiestas de San Isidro de 1986

Rafa Hernández

98 x 75,5 cm. Papel. Fotomecánica

Museo de Historia de Madrid

38

Fiestas de San Isidro de 1987

Óscar Mariné Brandi y Christian Boyer

149,5 x $80 \mathrm{~cm}$. Papel. Serigrafía

Museo de Historia de Madrid

39

Fiestas de San Isidro de 1988

Javier G. del Olmo y Javier Lobato Solana

(ilustrador)

175 x $120 \mathrm{~cm}$. Papel. Fotomecánica

Museo de Historia de Madrid

40

Fiestas de San Isidro de 1989

Javier de Juan

102 x $72 \mathrm{~cm}$. Papel. Témpera

Museo de Historia de Madrid

41

Fiestas de San Isidro de 1990

F. Vázquez

62,5 x $43 \mathrm{~cm}$. Papel. Fotomecánica

Museo de Historia de Historia

42

Fiestas de San Isidro de 1991

Javier Clavo

162 x 113 cm. Lienzo. Óleo

Museo de Historia de Madrid

43

Feria de San Isidro de 1952

79 x $55 \mathrm{~cm}$. Papel. Dos tintas

Biblioteca Nacional de España (CART. P/427)

Biblioteca Regional Joaquín Leguina de Madrid (Mg. XXI-184)

44

Feria de San Isidro de 1952

$52 \times 24 \mathrm{~cm}$. Tela de seda. Estampado

Museo de Historia de Madrid (Inv. 10156,

10157, 10158)

45

Feria de San Isidro de 1954

Andreo

$80 \times 60 \mathrm{~cm}$. Tela. Estampado

Museo de Historia de Madrid (Inv. 10160)
46

Feria de San Isidro de 1958

Andrés Martínez de León

$51 \times 25 \mathrm{~cm}$. Tela de seda. Estampado

Museo de Historia de Madrid (Inv. 10162, 10163)

47

Feria de San Isidro de 1965

C. Hermosa

48 x $27 \mathrm{~cm}$. Tela de seda. Estampado

Biblioteca Regional Joaquín Leguina de Madrid (Mg. XVI-64)

48

Feria de San Isidro de 1968

43 x $24 \mathrm{~cm}$. Tela de seda. Estampado

Biblioteca Regional Joaquín Leguina de Madrid (Mg. XVI-65)

49

Feria de San Isidro de 1969

Álvarez Carmena

52 x $24 \mathrm{~cm}$. Tela de seda. Estampado

Biblioteca Regional Joaquín Leguina de Madrid (Mg. XVI-66)

50

Feria de San Isidro de 1970

Álvarez Carmena

62,2 x $29 \mathrm{~cm}$. Papel. Fotomecánica

Biblioteca Regional Joaquín Leguina de Madrid

51

Feria de San Isidro de 1973

Álvarez Carmena

$51 \times 25 \mathrm{~cm}$. Tela de seda. Estampado

Biblioteca Regional Joaquín Leguina de

Madrid (Mg. XVI-67)

52

Feria de San Isidro de 1974

Álvarez Carmena

$52 \times 25 \mathrm{~cm}$. Tela de seda. Estampado

Biblioteca Regional Joaquín Leguina de Madrid (Mg. XVI-68)

53

Feria de San Isidro de 1976

Álvarez Carmena

51 x $25 \mathrm{~cm}$. Tela de seda. Estampado

Biblioteca Regional Joaquín Leguina de Madrid (Mg. XVI-69)

54

Feria de San Isidro de 1977

Álvarez Carmena

51 x $25 \mathrm{~cm}$. Tela de seda. Estampado 
Biblioteca Regional Joaquín Leguina de Madrid (Mg. XVI-70)

55

Feria de San Isidro de 1980

César Palacios

$51 \times 27 \mathrm{~cm}$. Tela de seda. Estampado

Biblioteca Regional Joaquín Leguina de Madrid (Mg. XVI-71)

\section{6}

Feria de San Isidro de 1981

José Cros Estrems

104 x $52 \mathrm{~cm}$. Papel. Fotomecánica

Biblioteca Regional Joaquín Leguina de Madrid (Mg. XV-59)

57

Feria de San Isidro de 1981

Álvarez Carmena

43,7 x $20 \mathrm{~cm}$. Papel. Fotomecánica

Biblioteca Regional Joaquín Leguina de Madrid

58

Feria de San Isidro de 1982

Álvarez Carmena

43 x $22 \mathrm{~cm}$. Papel. Fotomecánica

Biblioteca Regional Joaquín Leguina de Madrid (R. 185775)

59

Feria de San Isidro de 1983

Álvarez Carmena

43,8 x 22,5 cm. Papel. Fotomecánica

Biblioteca Regional Joaquín Leguina de Madrid

60

Feria de San Isidro de 1984

Álvarez Carmena

44,6 x 20,9 cm. Papel. Fotomecánica

Biblioteca Regional Joaquín Leguina de Madrid

61

Feria de San Isidro de 1986

45,8 x 20,3 cm. Papel. Fotomecánica

Biblioteca Regional Joaquín Leguina de Madrid

62

Feria de San Isidro de 1988

Calderón Jacome

47,7 x $21 \mathrm{~cm}$. Papel. Fotomecánica

Biblioteca Regional Joaquín Leguina de Madrid
Feria de San Isidro de 1996

Álvarez Carmena

$51 \times 27 \mathrm{~cm}$. Tela de seda. Estampado

Biblioteca Regional Joaquín Leguina de Madrid (Mg. XVI-72)

64

Feria de San Isidro de 1997

Álvarez Carmena

$51 \times 27 \mathrm{~cm}$. Tela de seda. Estampado

Biblioteca Regional Joaquín Leguina de Madrid (Mg. XVI-73)

65

Feria de San Isidro de 1998

Álvarez Carmena

$51 \times 27 \mathrm{~cm}$. Tela de seda. Estampado

Biblioteca Regional Joaquín Leguina de Madrid (Mg. XVI-74)

66

Feria de San Isidro de 1999

Álvarez Carmena

50 x $27 \mathrm{~cm}$. Tela de seda. Estampado

Biblioteca Regional Joaquín Leguina de Madrid (Mg. XVI-75)

67

Feria de San Isidro de 2000

Álvarez Carmena

$51 \times 28 \mathrm{~cm}$. Tela de seda. Estampado

Biblioteca Regional Joaquín Leguina de Madrid (Mg. XVI-76)

68

Feria de San Isidro de 2002

Álvarez Carmena

$50 \times 27 \mathrm{~cm}$. Tela de seda. Estampado

Biblioteca Regional Joaquín Leguina de Madrid (Mg. XVI-77)

69

Feria de San Isidro de 2003

José Puente

50 x $27 \mathrm{~cm}$. Tela de seda. Estampado

Biblioteca Regional Joaquín Leguina de Madrid (Mg. XVI-78)

70

Feria de San Isidro de Madrid de 2004

José Puente

$50 \times 27 \mathrm{~cm}$. Tela de seda. Estampado

Biblioteca Regional Joaquín Leguina de Madrid (Mg. XVI-79)

71

Feria de San Isidro de 2005

90 x $60 \mathrm{~cm}$. Papel. Fotomecánica

Museo de Historia de Madrid 